\title{
Research on the Training Mode of Innovative Talents of Information Specialty
}

\author{
Jianyan Zhang*, Junshe Wang, Jia Su, Ying Li and Min Wang \\ School of Information Science and Engineering, Hebei University of Science and Technology \\ Shijiazhuang,China
}

Key words: Training quality; Innovation ability; Innovative talents

\begin{abstract}
With the rapid development of modern science and technology, the demand for information talents is increasing in society, at the same time, higher requirements are placed on the quality of personnel training, especially innovation. This paper analyzes the current situation of the cultivation of innovative talents for information specialty in universities and colleges, and puts forward effective measures for cultivating innovative talents in information specialty based on actual teaching experience. After three years of teaching practice for undergraduate students, we have received significant teaching results in the cultivation of students' innovative ability.
\end{abstract}

\section{Introduction}

In recent years, China has successively implemented development strategies such as "Raising Capacity for Independent Innovation, Building Innovative Country", "Masses start up and Innovation" [1]. The fundamental way to achieve the above strategic goals is the cultivation of innovative talents, and the cultivation of innovative talents is the core content of the "Outline for National Medium and Long-Term Education Reform and Development Plan (2010-2020)"[2]. Exploring the innovative talent training mode and promoting innovative talents in the information profession are the historical requirements for building an innovative country and realizing the great rejuvenation of the nation. It is also an urgent need for education reform. Combined with the current era of big data, "Internet+" and cloud computing, information professionals are indispensable.

\section{Situation of innovative talents cultivation in information specialty in colleges and universities}

At present, all universities are actively exploring the research on the training mode and reform of education and teaching of information professionals, greatly improving the quality of teaching, and training a large number of high-level information talents. However, universities generally have the following problems in the process of cultivating information talents.

Training scheme can't meet the requirements of innovation ability training. The implementation of the training program has many cognitive courses and the proportion of theory is larger than practice[3-5]. Students' ability in learning activities cannot be effectively exercised, resulting in poor engineering practice and disconnected theory and practice.

Teaching methods cannot adapt to the requirements of ability training. At present, colleges and universities have made specialty adjustments to the professional structure according to the needs of society. However, the traditional teaching ideas and methods have not been adjusted in time. Most of the courses still use the "teacher teaching and student studying" method of feeding ducks, failing to embody the main role of students and the leading role of teachers in the teaching process. Teaching activities in class lack real-time interaction, as well as the enthusiasm and initiative of students cannot be mobilized.

Assessment methods can not meet the requirements of improving quality. The assessment methods are relatively single, and most of them are closed-book written examinations. They do not adopt a variety of assessment methods flexibly according to the nature and content of the curriculum, and failed to examine students' comprehensive application capabilities well. 
Practice teaching cannot satisfy the training of engineering design ability. The majority of experimental teaching is confirmatory, the relationship between the comprehensive or designed experiments and engineering practice is relatively few. This leads students to do experiment in form and lack of initiative. In the training program, the majority of the actual teaching is based on students visit and simulation, which is not conducive to the training of students' engineering design capabilities and innovative thinking, although there are practical courses such as metalworking, electronic practice, production practice, graduation practice, etc.

Lack of teachers, insufficient support for innovation education. Some teachers with outdated teaching ideas still remain in exam-oriented education and simple knowledge transfer. Some teachers with simple teaching methods and outdated teaching philosophy, teach the same course for many years. The teaching content is basically unchanged. In addition, university generally implements performance appraisal. Teachers are concerned about their own performance workload, while ignoring the cultivation of innovative talents. From the school perspective, although students are encouraged to innovate in their ability to innovate, honestly, the support of school is small and the hardware cannot keep up with the students' innovation.

\section{Measures for training innovative talents of information specialty}

In recent years, the College of Information Science and Engineering of Hebei University of Science and Technology has combined the social needs, professional characteristics, and teaching experience to construct a training model for innovative talents in information technology from five perspectives, as shown in the following fig. 1:

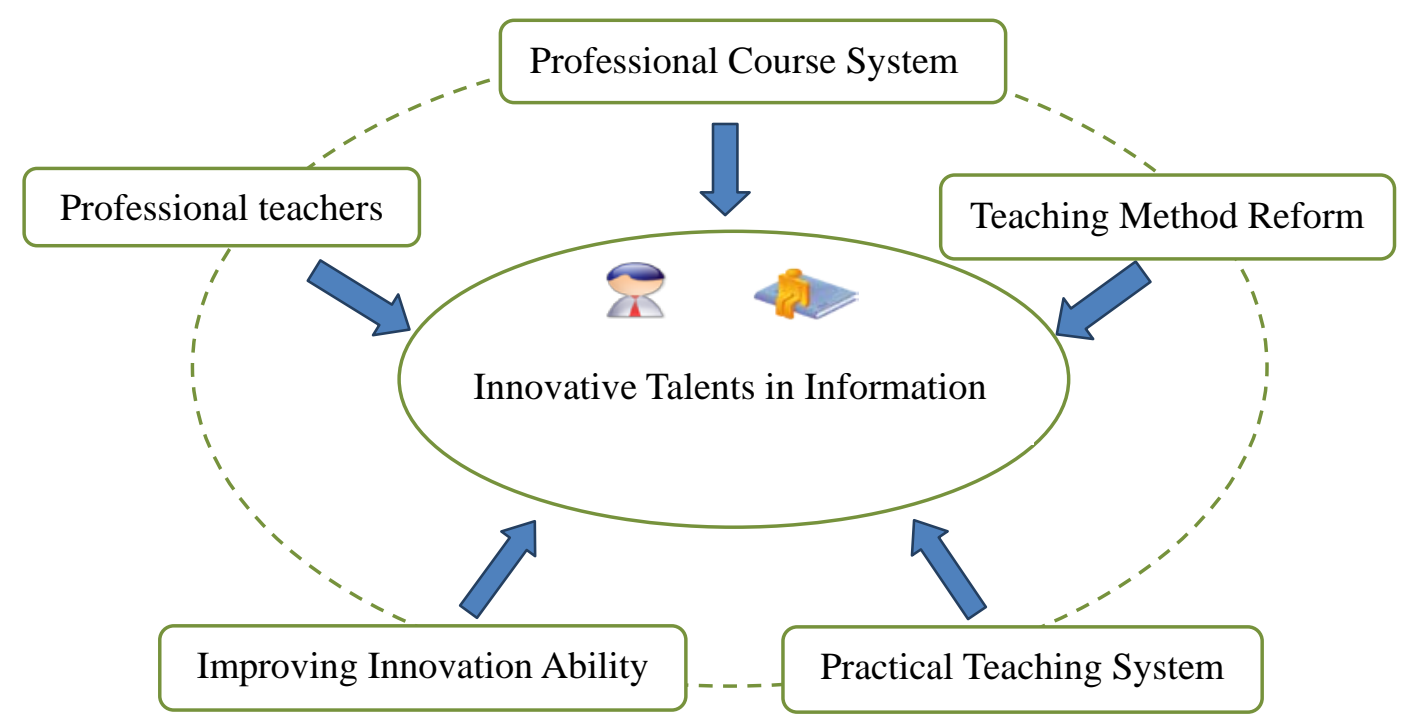

Figure 1. Training mode for innovative professionals in information

Constructing a curriculum system for innovative talents knowledge and capability structure. Focusing on cultivating the comprehensive quality, innovation and practice ability of students, we will combine the imparting of knowledge, training ability and improvement of qualities. Based on the ideas of "broadening the foundation, strengthening practice, highlighting innovation, advancing compounding, and facing the world"[6,7], we will construct a curriculum system that is oriented to the knowledge and ability structure of information professionals. Courses in the training program consist of five modules: General Studies, Basic Courses, Professional Basic Courses, Professional Courses and Practical Lessons. Each module incorporates ideas for innovation and entrepreneurship. The construction of innovation and entrepreneurship practice curriculum is based on the idea of "incremental order, organic convergence, comprehensive communication, and school-enterprise cooperation" to construct a multi-level, three-dimensional and full-coverage innovation and entrepreneurship education curriculum system. Promote organic integration of professional 
education and innovation education, cultivate students' innovative spirit, entrepreneurial awareness, and innovation and entrepreneurship.

Innovative teaching and assessment methods. In teaching methods, we actively use heuristics and discussion-based teaching, use project-driven as the main means to reform the classroom teaching model, and transform the existing "teacher-centered" teaching model into a "student-centered" teaching model. Classroom teaching focuses on exploration research. Teachers ask questions in the classroom. Then students come to think, analyze, and solve problems to cultivate students' creative thinking skills. In teaching methods, the full use of electronic courseware, MOOC, mixed teaching, etc. to fully stimulate students' enthusiasm for learning. In the assessment methods, different assessment methods are in accordance with the nature of courses. Language courses such as "MATLAB with Applications", "Programming in C", and "Introduction to JAVA Programming" are evaluated on the machine; "Circuit Design and Simulation", "Android Intelligent Smartphone Programming" and other highly-competitive specialized courses adopt the methods of defense, physical objects and engineering training. The experimental course adopts a combination of pre-reporting reports, experimental operations, and experimental results to assess students' ability to solve problems and innovate.

Construct a practical teaching system that is conducive to improving innovative ability of students. Based on the characteristics of informational specialty, comprehensive experiments, design experiments and innovative experiments ought to be added. Build a combination of experimental and comprehensive design experiments, open experimental teaching and scientific research projects or innovative projects combined experimental teaching mode. In terms of practical teaching, the course design is made into a project, and students are trained in innovative ideas and practical skills through project completion; in practice and graduation design, through cooperation between schools and enterprises, laboratories and other forms are built so that students can directly participate in practical projects, and then improve students' comprehensive application capabilities. Encourage teachers to integrate scientific research projects into practice, such as experiments, curriculum design, graduation design, and internships. Teachers with practical engineering experience are encouraged to guide students to participate in science and technology competitions. In practice, students' awareness of innovation and ability to innovate are cultivated, and the spirit of innovation and practice are integrated throughout the entire process of personnel training.

Form scientific and technological innovation teams to participate in discipline competitions to cultivate students' sense of innovation and ability. According to the college's advantages and professional characteristics, we have established teams such as "Internet Applications", "Internet of Things Technology" and "Electronic Design" to participate in various information discipline competitions, such as the National University Provincial Electronic Design Competition and the "Internet+" Competition, Programming Competitions, Computer Application Contests in Five Provinces in North China, and Mathematics Modeling Competitions further improve students' awareness of innovation, innovation and entrepreneurship.

Enhance the quality of teachers and practical ability, establish a professional teaching staff. First of all, improve teachers' ideological quality, encourage teachers to carry out teaching research and teaching reforms; secondly, actively send young teachers to study abroad at well-known domestic universities, and participate in engineering practice to improve the professional quality of teachers; thirdly, hire the technical personnel of the enterprise to be part-time teachers and enrich the teaching team; through the self-construction and the introduction of wisdom, a professional teacher team with advanced educational concept, reasonable team structure, strong sense of innovation is built. Under the guidance of professional teachers, students participate in scientific and technological innovation activities, engineering training, or teacher research projects, thereby enhancing their own ability.

\section{Teaching results}

The College of Information Science and Engineering of Hebei University of Science and Technology emphasizes stimulating students' subjective initiative and curiosity in cultivating 
students and trains their practical and innovative abilities. With the joint efforts of various departments and teachers of the college, the quality of teaching and the teaching level of information specialty have been significantly improved. Since 2015, students have won 3 first and 6 second prizes in the "National Undergraduate Electronic Design Contest", 7 third prizes in the "Internet+ College Innovation and Entrepreneurship Competition", and 5 first prizes, 3 second prizes in "National Robot Competition for University Students", 1 national third prize, 1 provincial-level special prize, and 3 provincial first prizes for the "National Collegiate 'Challenge Cup’ Science and Technology Works Competition”. There was 1 national second prize in the “National University Student Energy Saving and Emission Reduction Competition”. We also won 1 invention patent, and 4 utility model patents. The project has been approved at the national level for innovation and entrepreneurship training programs for university students and has been approved at the provincial level for 11 projects.

\section{Summary}

The cultivation of talents for scientific and technological innovation is the core goal of engineering specialty in colleges and universities. Exploring and researching innovative talents training models has great significance to further deepening the reform of higher education and comprehensively enhancing students' ability in science and technology innovation. In recent years, the information specialty of our university has actively studied and practiced innovative talent training models, focusing on the cultivation of knowledge's comprehensive application ability and innovation ability, and achieved good results. This paper, based on an in-depth study of the situation of training models for innovative talents in information specialty, gives some measures for training innovative talents in information specialty, thereby improving the quality of innovative talents training, improving the training model for innovative talents, and achieving universal access to training of creative talents.

\section{Acknowledgments}

This work was financially supported by the Hebei Provincial Social Science Research annual fund project (Grant NO.SQ171053), the Science and Technology Research Project of Hebei Higer Education, China(Grant No.ZD2016042), the Natural Science Foundation of Hebei, China(Grant No.F2017208031), and the Higher Education Teaching Reform Project in Hebei Province (Training system of practical ability for information talents).

\section{References}

[1] W. Wang. Exploration on the training mode of top notch innovative talents in electronic information specialty[J]. China Electric Power Education, 2014（29）:28-30

[2] C.H. Jiang. Research and practice of innovative training mode of electronic information talents in local agricultural universities[J]. Journal of Higher Education, 2015(20):34-35

[3] R. Ma, Q.Luan. An analysis of the training mode of innovative talents in Colleges and Universities[J]. Continue Education Research, 2016 (12):120-122

[4] H. Liu, Y.Z. Shen. Construction of innovative talents, cultivation mode in college and university of engineering[J]. Journal of Liaoning Technical University (Social Science Edition), 2013, 15(3):321-323

[5] B.Y. Lu, H.H. Zhang. Research on the training mode of creative talents in Engineering[J]. China Electric Power Education, 2013,7(6):19-20

[6] J.M. Zhang. Research on training mode of applied and innovative talents in electronic information specialty[J]. China Adult Education, 2013(15):187-188 
[7] K. Gao, Y.F. Xu and Y.Q. Zhang. Research and Practice on Cultivation Model of Innovative Talents in Electronic Information[J].Education Forum, 2011(1):232 